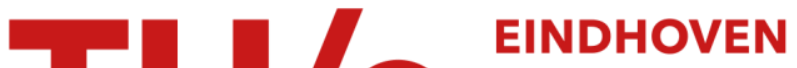 UNIVERSITY OF TECHNOLOGY
}

\section{Simultaneous high speed OTDM add-drop multiplexing using GT-UNI switch}

Citation for published version (APA):

Turkiewicz, J. P., Tangdiongga, E., Rohde, H., Schairer, W., Lehmann, G., Khoe, G. D., \& Waardt, de, H. (2003). Simultaneous high speed OTDM add-drop multiplexing using GT-UNI switch. Electronics Letters, 39(10), 795796. https://doi.org/10.1049/el:20030535

DOI:

10.1049/el:20030535

Document status and date:

Published: 01/01/2003

\section{Document Version:}

Publisher's PDF, also known as Version of Record (includes final page, issue and volume numbers)

\section{Please check the document version of this publication:}

- A submitted manuscript is the version of the article upon submission and before peer-review. There can be important differences between the submitted version and the official published version of record. People interested in the research are advised to contact the author for the final version of the publication, or visit the $\mathrm{DOI}$ to the publisher's website.

- The final author version and the galley proof are versions of the publication after peer review.

- The final published version features the final layout of the paper including the volume, issue and page numbers.

Link to publication

\section{General rights}

Copyright and moral rights for the publications made accessible in the public portal are retained by the authors and/or other copyright owners and it is a condition of accessing publications that users recognise and abide by the legal requirements associated with these rights.

- Users may download and print one copy of any publication from the public portal for the purpose of private study or research.

- You may not further distribute the material or use it for any profit-making activity or commercial gain

- You may freely distribute the URL identifying the publication in the public portal.

If the publication is distributed under the terms of Article 25fa of the Dutch Copyright Act, indicated by the "Taverne" license above, please follow below link for the End User Agreement:

www.tue.nl/taverne

Take down policy

If you believe that this document breaches copyright please contact us at:

openaccess@tue.nl

providing details and we will investigate your claim. 
MTs, while using the proposed protocol the data transmission as a whole would be kept uninterrupted regardless of the channel state of any single $M T$.

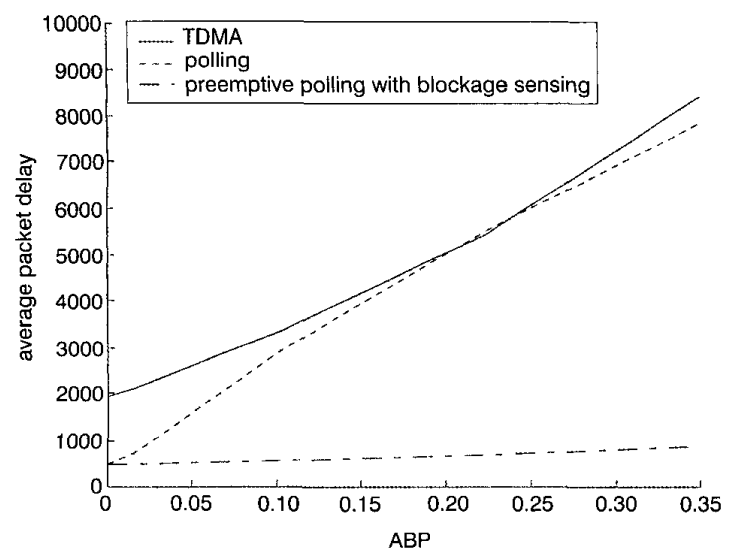

Fig. 3 Impact of ABP on average packet delay for different $M A C$ protocols

The improvement of the average transfer delay is also significant, which is shown in Fig. 3. The preemptive polling with blockage sensing protocol has a small and stable average transfer delay, even under a severe degree of beam blockage. Conversely, the average transfer delay of either TDMA or polling increases radically when the ABP rises. The reason is that for TDMA and polling, even if an MT is blocked, the system still allocates a part of the channel resource to it, which inevitably reduces the data transmission of all MTs. The proposed scheme eliminates that inefficiency factor of the standard protocols: only when an MT has a good link state can it access the shared channel.

Conclusion: Classic fixed-assignment and demand-assignment MAC protocols cannot efficiently reallocate the shared channel, which leads to their poor performance under beam blockage circumstances. This motivates us to modify the polling by using blockage sensing and channel reassignment according to individual channel state. This proposed method provides significant improvement in both system throughput and average transfer delay. Therefore, as a candidate MAC protocol for LOS optical WLAN, the preemptive polling with blockage sensing could satisfy the requirements of both system efficiency and user's QoS.

Acknowledgment: Jindong Hou acknowledges the K.C. Wong Scholarship Foundation for its financial support.

\section{(C) IEE 2003}

Electronics Letters Online No: 20030503

DOI: 10.1049/el:20030503

Jindong Hou and D.C. O'Brien (Department of Engineering Science, University of Oxford, Oxford, OXI 3PJ, United Kingdom)

E-mail:'jindong.hou@balliol.ox.ac.uk

\section{References}

1 EDNEY, J.: '802.11: the new wireless standard [wireless LAN]', Data Commun. Int., 1995, 24, (12), pp. 77-78, 82, 84, 86

2 SPRAGINS, J.D.: 'Telecommunications protocols and design' (AddisonWesley, 1991)

3 FANTACCI, R., and SCARDI, M.: 'Performance evaluation of preemptive polling schemes and ARQ techniques for indoor wireless networks', IEEE Trans. Veh. Technol., 1996, 45, (2), pp. 248-257

4 FANTACCI, R., and NANNICINI, S.: 'Multiple access protocol for integration of variable bit rate multimedia traffic in UMTS/IMT-2000 based on wideband CDMA', IEEE J. Sel. Areas Commun, 2000, 18, (8), pp. 1441-1454

\section{Simultaneous high speed OTDM add-drop multiplexing using GT-UNI switch}

J.P. Turkiewicz, E. Tangdiongga, H. Rohde, W: Schairer, G. Lehmann, G.D. Khoe and H. de Waardt

The authors describe the excellent capability of an all-optical gaintransparent ultrafast nonlinear interferometer (GT-UNI) in dropping, passing through, and adding optical time domain multiplexing (OTDM) channels. Error free operation without significant penalties of a complete OTDM add-drop node at $80 \mathrm{Gbit} / \mathrm{s}$ was achieved.

Introduction: The key functionality required in OTDM network nodes is add-drop multiplexing [1]. In an add-drop node a low bit rate single data channel will be separated (drop function) from an incoming high bit rate data stream. Simultaneously the remaining data channels should be left undisturbed (through function), and in the remaining vacant time slot a new channel can be added (add function). Recently, all-optical add-drop multiplexers operating at $40 \mathrm{Gbit} / \mathrm{s}$ based on cross phase modulation [2], a monolithic Mach-Zehnder interferometer [3], and an electroabsorption modulator [4] have been demonstrated. This Letter presents OTDM add-drop multiplexing in a GT-UNI switch operating at $80 \mathrm{Gbit} / \mathrm{s}$, to the best of our knowledge the highest bit rate in OTDM networking so far. Several OTDM demultiplexing experiments with the GT-UNI switch have been reported e.g. [5], however complete add-drop multiplexing was not investigated. In our experiments we achieved error free operation without significant penalties of all add-drop node functionalities: drop, through, and add.

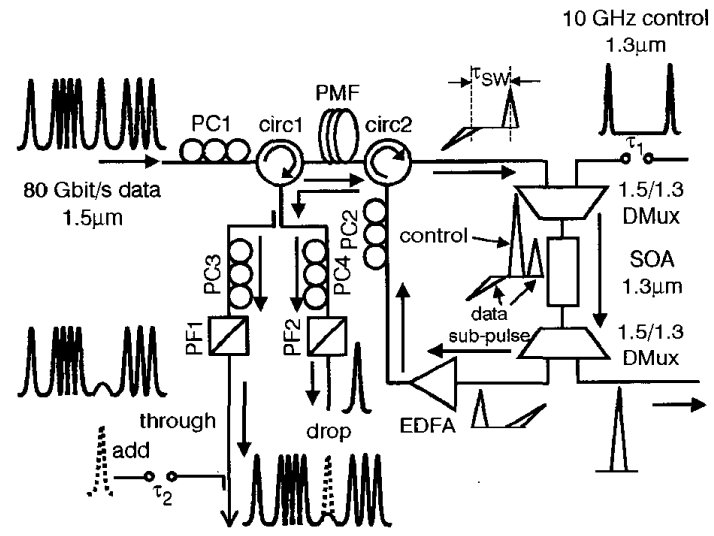

Fig. 1 Experimental setup

Experimental setup: Fig. 1 presents the experimental setup. A $8 \times 10 \mathrm{Gbit} / \mathrm{s}$ OTDM data signal at $1.55 \mu \mathrm{m}$, enters the GT-UNI switch by an optical circulator (circ1). The polarisation state at the input of a highly birefringent polarisation maintaining fibre (PMF), is set by a polarisation controller ( $\mathrm{PC1}$ ) such that the data pulses have equal components in the main axes of the PMF and after leaving the PMF they are separated in time by a delay $\tau_{S W}=5 \mathrm{ps}$. Next, two subpulses are coupled via circ 2 into a fold-back loop containing a $1.3 \mu \mathrm{m}$ semiconductor optical amplifier (SOA). After passing the SOA, the sub-pulses are amplified by an erbium-doped fibre amplifier (EDFA) and are re-launched into the same highly birefringent PMF by $\operatorname{circ} 2$. Here, the polarisation states of the data sub-pulses are adjusted by the $\mathrm{PC} 2$ in such a way that the delay between two sub-pulses is reversed and a single pulse appears at the PMF end. There are two output ports, which are formed by a power splitter, polarisation controllers (PC3 and PC4), and polarisation filters (PF1 and PF2). In the absence of $1.31 \mu \mathrm{m}$ control pulse both data sub-pulses experience the same condition in the loop. As a result, the recombined pulse leaves the GT-UNI switch via the through port (PF1). For switching, a highintensity control pulse of $4 \mathrm{ps}$ pulse width is inserted between the two data sub-pulses using a $1.5 / 1.3 \mu \mathrm{m}$ multiplexer. A variable delay line controls the insertion timing. When a single control pulse is launched between data sub-pulses, the leading sub-pulse will preserve its original phase but the trailing sub-pulse will experience a nonlinear 
phase shift. The polarisation state of the switched recombined data pulse will therefore be rotated with respect to the polarisation state of the un-switched pulse. By this way, the data pulse will leave the drop port (PF2). In the case of the phase shift less than $\pi$ rad, a fraction of drop pulses will appear in the through port, causing optical crosstalk for a channel eventually added in this time slot. A $10 \mathrm{Gbit} / \mathrm{s}$ add channel, controlled by another delay line, is inserted into the through port by a passive fibre combiner. The $10 \mathrm{Gbit} / \mathrm{s}$ drop channels can be directly evaluated using a bit error rate (BER) tester. The $7 \times 10 \mathrm{Gbit} / \mathrm{s}$ remaining through channels and the inserted $10 \mathrm{Gbit} / \mathrm{s}$ $\mathrm{Gbit} / \mathrm{s}$ add channel are first demultiplexed to $10 \mathrm{Gbit} / \mathrm{s}$ by a cascade of two electro-absorption modulators (10 ps gating time) and then evaluated by the $10 \mathrm{Gbit} / \mathrm{s}$ receiver and the BER tester.

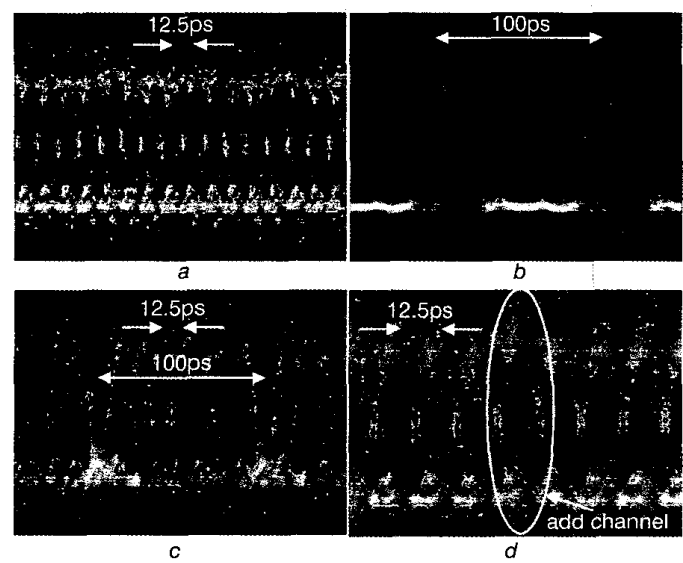

Fig. 2 Measured eye diagrams

$a$ Input $80 \mathrm{Gbit} / \mathrm{s}$ OTDM signal

$b 10 \mathrm{Gbit} / \mathrm{s}$ drop channel

$c 7 \times 10 \mathrm{Gbit} / \mathrm{s}$ through channels

$d 7 \times 10 \mathrm{Gbit} / \mathrm{s}$ through channels with inserted $10 \mathrm{Gbit} / \mathrm{s}$ add channe
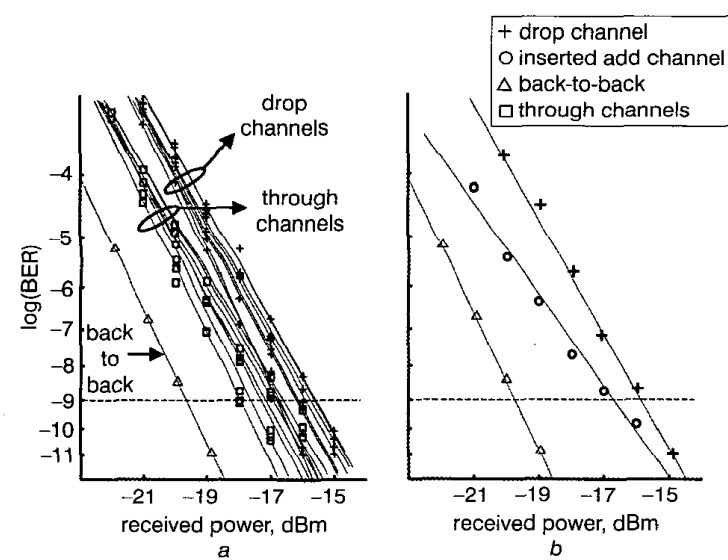

Fig. 3 BER performance

$a$ Drop and through channels

$b$ Drop and inserted add channel

Results and discussion: Fig. 2 presents eye diagrams of the outputs of the GT-UNI switch. Fig. $2 a$ shows the $80 \mathrm{Gbit} / \mathrm{s}$ data input stream, Fig. $2 b$ a $10 \mathrm{Gbit} / \mathrm{s}$ drop channel, Fig. $2 c$ seven remaining $10 \mathrm{Gbit} / \mathrm{s}$ channels in the through port. The perfect emptying of the drop time slot is visible. After dropping one channel we inserted a $10 \mathrm{Gbit} / \mathrm{s}$ data channel at the same wavelength in the empty time slot to form again the $80 \mathrm{Gbit} / \mathrm{s}$ data stream, Fig. $2 d$. All eye diagrams in Fig. 2 indicate clear open eyes and excellent operation of the GT-UNI switch. For the BER measurements we used a pseudorandom bit sequence of length $2^{7}-1$. As a reference we measured an optimised $10 \mathrm{Gbit} / \mathrm{s}$ signal in a back-to-back configuration. Fig. $3 a$ shows the BER measurements for eight drop channels and for seven $10 \mathrm{Gbit} / \mathrm{s}$ through channels. The average sensitivity penalties at BER $=10^{-9}$ for the drop channels are $3.7 \mathrm{~dB}$ and for the through channels $2.7 \mathrm{~dB}$. The difference between the worst and best channel in both cases is about $1.4 \mathrm{~dB}$, proving proper operation of the GT-UNI switch. Fig. $3 b$ presents the BER performance of one of the drop channels and the channel inserted in the empty time slot add, demonstrating OTDM networking. The sensitivity penalty at $B E R=10^{-9}$ for the drop channel is $4.0 \mathrm{~dB}$ and for the inserted add channel $3.0 \mathrm{~dB}$. The sensitivity penalties are a combination of the reduction of opticalsignal-to-noise ratio, polarisation misalignment, and in the case of the inserted add channel the interferometric crosstalk with the residual optical signal of the dropped channel. However these interferometric effects are so small, that they are barely observed in Fig. $2 c$ and $d$ and in the BER measurements.

Conclusions: We have demonstrated the excellent performance of an all-optical $80 \mathrm{Gbit} / \mathrm{s}$ OTDM add-drop node based on a GT-UNI switch. We achieved error free operation for all add-drop functionalities. Insignificant penalties for all operations were observed. These remarkable results indicate the great potential of GT-UNI switches for OTDM networking.

Acknowledgment: This work was supported by the European Commission under the IST-2000-28765 project FASHION (ultraFAst Switching in HIgh-speed OTDM Networks).

(C) IEE 2003

25 March 2003

Electronics Letters Online No: 20030535

DOI: 10.1049/el:20030535

J.P. Turkiewicz, E. Tangdiongga, G.D. Khoe and H. de Waardt (COBRA Research Institute, Eindhoven University of Technology, EH-12.26, P.O. Box 513, $5600 \mathrm{MB}$ Eindhoven, The Netherlands)

E-mail: j.turkiewicz@tue.nl

H. Rohde, W. Schairer and G. Lehmann (Siemens Corporate Technology, Otto-Hahn-Ring 6, 81730 Munich, Germany)

\section{References}

I SPÄLTER, S., HEID, M., JANSEN, S.L., LEHMANN, G., MEISSNER, E., and LANKI, B.: 'Ultra fast switching in OTDM networks'. 28th European Conf. on Optical Comm., Copenhagen, Denmark, 2002, Paper 11.4.1(Invited)

2 RAU, L., RANGARAJAN, S., WANG, W, and BLUMENTHAL, D.I.: 'All-optical add-drop of OTDM channel using an ultra-fast fiber based wavelength converter'. Proc. Opt. Fiber Comm. Conf., Anaheim, CA, 2002, Paper WM1

3 FISCHER, S., DÜLK, M., GAMPER, E., VOGT, W., HUNZIKER, W. GINI MELCHIOR, H., BUXENS, A., POULSEN, H.N., and CLAUSEN, A.T.: "Alloptical regenerative OTDM add-drop multiplexing at $40 \mathrm{~Gb} / \mathrm{s}$ using monolithic InP Mach-Zehnder interferometer, IEEE Photonics Technol. Lett., 2000, 12, (3), pp. 335-337

4 PHILlIPS, I.D., GLOAG, A., MOODIE, D.G., DORAN, N.J., BENNION, I, and ELLIS, A.D.: 'Drop and insert multiplexing with simultaneous clock recovery using an electroabsorption modulator', IEEE Photonics Technol. Lett., 1998, 10, (2), pp. 291-293

5 SCHUBERT, C., DIEZ, S., BERGER, J, LUDWIG, R., FEISTE, U, WEBERH, G., TOPTCHIYSKI, G., PETERMANN, K., and KRAJINOVIC, V: '160-Gb/s alloptical demultiplexing using a gain-transparent ultrafast nonlinear interferometer (GT-UNI)', IEEE Photonics Technol. Lett., 2001, 13 (5), pp. 475477

\section{Transmission over $5.6 \mathrm{~km}$ large effective area and low-loss $(1.7 \mathrm{~dB} / \mathrm{km})$ photonic crystal fibre}

\section{B. Zsigri, C. Peucheret, M.D. Nielsen and P. Jeppesen}

A $10 \mathrm{Gbit} / \mathrm{s}$ non-return-to-zero signal at $1550 \mathrm{~nm}$ over $5.6 \mathrm{~km}$ photonic crystal fibre (PCF) with $1.7 \mathrm{~dB} / \mathrm{km}$ loss has been successfully transmitted, demonstrating the potential of $\mathrm{PCF}$ as transmission fibre.

Introduction: Photonic crystal fibres (PCF) are strong candidates to serve as basic building components for future optical communication systems. Their optical properties such as chromatic dispersion, 